BUDGETING : Journal of Business, Management and Accounting

Volume 2, Nomor 1, Desember 2020

e-ISSN: 2715-2480

p-ISSN: 2715-1913

DOI : https://doi.org/10.31539/budgeting.v2i1.1757

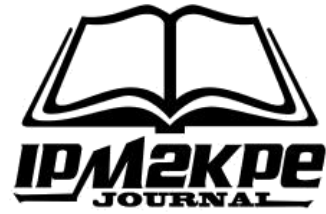

\title{
FAKTOR-FAKTOR BUDAYA KERJA KARYAWAN
}

\author{
Nor Norisanti ${ }^{1}$, Acep Samsudin ${ }^{2}$, Ummu Hawa Assa'diyah ${ }^{3}$ \\ Universitas Muhammadiyah Sukabumi ${ }^{1,2,3}$ \\ nor_norisanti@yahoo.com ${ }^{1}$
}

\begin{abstract}
ABSTRAK
Tujuan penelitian ini adalah untuk mengetahui budaya kerja karyawan PD. RAM Armalia Sukabumi dan faktor-faktor yang mempengaruhinya baik secara langsung dan tidak langsung. Penelitian ini menggunakan metode pendekatan asosiatif dan deskriptif dengan path analysis untuk mengukur pengaruh langsung dan tidak langsung antar variabel. Hasil penelitian menunjukkan bahwa pengaruh inovasi pada budaya kerja karyawan adalah sebesar 16,9\%, tanggung jawab sebesar $0,97 \%$, orientasi pada hasil sebesar $0,05 \%$, pengetahuan sebesar $0,95 \%$, proses pembelajaran sebesar 2,07\%, pengaruh motivasi sebesar $0,18 \%$ dan besarnya pengaruh inovasi, tanggung jawab, orientasi pada hasil, pengetahuan, proses pembelajaran dan motivasi pada budaya kerja karyawan adalah sebesar $18,5 \%$ serta sisanya yaitu sebesar $81,5 \%$ dipengaruhi oleh variabel atau faktor lain. Simpulan, terdapat pengaruh yang positif pada variabel inovasi, tanggung jawab, orientasi pada hasil, pengetahuan, proses pembelajaran dan motivasi pada budaya kerja karyawan PD. RAM Armalia Sukabumi.
\end{abstract}

Kata Kunci: Budaya Kerja Karyawan, Faktor-Faktor Budaya Kerja

\section{ABSTRACT}

The purpose of this study was to determine the work culture of employees at PD. RAM Armalia Sukabumi and the factors that influence it both directly and indirectly. This study uses an associative and descriptive approach with path analysis to measure the direct and indirect effects between variables. The results showed that the influence of innovation on employee work culture was $16.9 \%$, responsibility was $0.97 \%$, results orientation was $0.05 \%$, knowledge was $0.95 \%$, learning process was $2.07 \%$, motivation is $0.18 \%$ and the magnitude of the influence of innovation, responsibility, result orientation, knowledge, learning process and motivation on employee work culture is $18.5 \%$ and the remaining $81.5 \%$ is influenced by variables or other factors. In conclusion, there is a positive influence on the innovation variable, responsibility, result orientation, knowledge, learning process and motivation on the work culture of employees at PD. RAM Armalia Sukabumi.

Keywords: Employee Work Culture, Work Culture Factors 


\section{PENDAHULUAN}

Budaya merupakan serangkaian tingkah laku dan hasil tingkah laku yang dipelajari oleh seseorang, dimana unsur pembentuknya didukung dan diteruskan oleh anggota lainnya (Setiadi, 2013). Dalam dunia kerja, budaya juga penting bagi perusahaan, dimana budaya yang dimaksud adalah budaya kerja. Budaya kerja merupakan kebiasaan yang dilakukan secara berulang-ulang oleh pegawai dalam suatu perusahaan. Tidak ada sanksi tegas terhadap pelaku pelanggaran kebiasaan ini, namun secara moral antara perusahaan dan karyawan telah menyepakati bahwa kebiasaan tersebut merupakan kebiasaan yang harus ditaati dalam rangka pelaksanaan pekerjaan untuk mencapai tujuan (Nawawi, 2003).

Jika budaya kerja tidak dilaksanakan oleh karyawan, maka tidak akan terjalin komitmen yang baik di dalam perusahaan. Setiap perusahaan mempunyai visi dan misi guna mencapai tujuan. Adanya kerjasama tim dapat mendukung upaya tercapainya tujuan tersebut. Namun sebuah perusahaan memiliki karyawan dengan karakteristik yang berbeda-berbeda. Karakteristik karyawan dilihat apabila karyawan memiliki inovasi dan melakukan proses pembelajaran yang diberikan oleh perusahaan. Karyawan merupakan penentu tercapai atau tidaknya tujuan perusahaan. Apabila karyawan tidak melakukan proses pembelajaran dalam melakukan inovasi, maka harapan perusahaan tidak akan tercapai.

Dalam mengenalkan budaya kerja yang ada di perusahaan, perusahaan harus memberikan pembelajaran dan motivasi terlebih dahulu kepada karyawan sehingga karyawan paham dan giat dalam melaksanakan tugas yang diberikan. Hal ini dapat memberikan dampak yang positif terhadap hasil yang ingin dicapai oleh perusahaan dan meningkatkan rasa tanggung jawab karyawan terhadap tugas yang sudah diberikan oleh perusahaan. Budaya kerja dapat berperan sebagai implementasi dan aktualisasi dari kepribadian seseorang yang dapat mempengaruhi kinerja dan tujuan perusahaan. Hal yang perlu ditumbuhkan dalam kepribadian seseorang atau pegawai adalah sikap kebersamaan, keterbukaan dan profesionalisme, menciptakan rasa nyaman, kekeluargaan serta membangun komunikasi yang lebih baik terhadap lingkungan kerja agar tujuan perusahaan tersebut secara efektif dapat terlaksana dengan baik (Mahanani et al., 2014). 
Salah satu perusahaan yang mengalami permasalahan dalam penerarapan budaya kerja yang baik adalah PD. RAM Armalia Sukabumi. Peneliti menemukan permasalahan pada budaya perilaku karyawan saat bekerja. Karyawan tidak menunjukkan rasa tanggung jawab dalam hal perilaku saat bekerja, seperti membawa masalah pribadi ke kantor dan tidak menghormati rekan kerja sehingga menyebabkan tidak adanya inovasi, orientasi pada hasil, pengetahuan, proses pembelajaran dan motivasi karyawan saat bekerja. Permasalahan tersebut diduga disebabkan karena rendahnya penerapan dan kesadaran karyawan terhadap budaya kerja pada PD. RAM Armalia Sukabumi.

\section{KAJIAN TEORI}

\section{Manajemen Sumber Daya Manusia}

Manajemen sumber daya manusia (SDM) merupakan proses mengelola, memotivasi dan membangun sumber daya manusia agar dapat menunjang aktivitas organisasi secara efektif dan efisien sesuai dengan tujuan strategis organisasi. Menurut Bohlarander \& Snell (2010) manajemen SDM merupakan ilmu yang mempelajari bagaimana memberdayakan karyawan dalam perusahan, membuat pekerjaan, kelompok kerja, mengembangkan para karyawan yang mempunyai kemampuan, mengidentifikasi suatu pendekatan untuk meningkatkan kinerja karyawan dan memberikan imbalan kepada mereka atas usahanya dalam bekerja. Menurut Hasibuan (2011) ilmu dan seni berperan dalam mengatur peran hubungan kerja agar dapat terlaksana secara efektif dalam rangka membantu mewujudkan tujuan perusahaan, karyawan dan masyarakat.

\section{Budaya}

Budaya merupakan warisan kesenian yang melekat kepada adat kebiasaan yang terdapat dalam nilai-nilai, norma sosial, kaidah dan agama. Secara umum, budaya merupakan suatu pengaturan agar setiap manusia memahami dan mengerti apa yang harus dilakukan dan diperbuat dalam menjalin hubungan dengan manusia lainnya. Menurut Schein (2010) budaya adalah pola asumsi yang dipelajari oleh suatu kelompok dalam menyelesaikan masalah adaptasi eksternal dan integrasi secara internal yang telah bekerja dengan cukup baik untuk dianggap valid. Oleh karena itu, pola tersebut harus 
diajarkan kepada anggota selanjutnya sebagai tata cara yang benar dalam melihat, berpikir dan merasakan kaitannya terhadap suatu permasalahan.

\section{Budaya Kerja}

Pentingnya kesadaran karyawan akan budaya kerja harus terus disosialisasikan dan dilaksanakan setiap saat. Hal ini berhubungan dengan pengimplementasian budaya kerja terhadap kinerja karyawan, karena setiap karyawan mempunyai karakteristik yang berbeda-beda, kemampuan karyawan yang masih terbatas, sikap dan perilaku masih perlu ditingkatkan serta perlu adanya dorongan dari pemimpin.

Menurut Gering et al., (2001) budaya kerja adalah suatu falsah yang didasari oleh pandangan hidup sebagai nilai-nilai yang menjadi sifat, kebiasaan dan juga pendorong yang dibudayakan dalam suatu kelompok dan tercermin dalam sikap menjadi perilaku, cita-cita, pendapat, pandangan serta tindakan yang terwujud sebagai kerja atau bekerja.

Budaya kerja menurut Mangkunegara (2005) adalah seperangkat asumsi atau sistem keyakinan, nilai-nilai dan norma yang dikembangkan dalam organisasi yang dijadikan pedoman tingkah laku bagi anggota-anggotanya untuk mengatasi masalah adaptasi eksternal dan integrasi internal.

\section{Dimensi Budya Kerja}

Menurut Ndraha (2005) budaya kerja dapat dibagi menjadi: 1) sikap terhadap pekerjaan, yakni kesukaan akan kerja dibandingkan kegiatan lain, seperti bersantai atau semata-mata memperoleh kepuasan dari kesibukan pekerjaannya sendiri atau terpaksa melakukan sesuatu hanya untuk kelangsungan hidupnya; 2) perilaku pada waktu bekerja, seperti rajin, berdedikasi, bertanggung jawab, berhati-hati, teliti, cermat, kemauan yang kuat untuk mempelajari tugas dan kewajibannya, suka membantu sesama karyawan atau sebaliknya. 


\section{Faktor-Faktor Budaya Kerja}

Apriyanti (2008) menyatakan bahwa terdapat enam faktor yang dapat mempengaruhi budaya kerja yaitu sebagai berikut: 1) inovasi; 2) tanggung jawab; 3) orientasi pada hasil; 4) pengetahuan; 5) proses pembelajaran; 6) motivasi.

\section{METODE PENELITIAN}

Penelitian ini menggunakan metode pendekatan asosiatif dan deskriptif. Metode penelitian deskriptif merupakan rumusan masalah yang berkenaan dengan pertanyaan terhadap variabel lain, bukan variabel independent ataupun dependent. Sedangkan penelitian asosiatif merupakan pengetahuan hubungan dua variabel atau lebih yang berfungsi menjelaskan, meramalkan dan mengontrol suatu gejala (Sugiyono, 2014).

Dalam melakukan kegiatan penelitian, fakta sebenarnya adalah tidak semua jumlah populasi dijadikan sebagai responden. Hal ini dikarenakan untuk mempersingkat waktu dan menjadi salah satu alternatif bagi penelitian. Agar mendapatkan hasil yang akurat dan informasi dengan baik, sampel pada penelitian ini dianalisis menggunakan teknik sampling jenuh untuk menghitung jumlah anggota populasi.

Menurut Arikunto (2010) jika jumlah populasinya kurang dari 100 orang, maka jumlah sampelnya diambil secara keseluruhan, tetapi jika populasinya lebih besar dari 100 orang, maka bisa diambil 10-15\% atau 20-25\% dari jumlah populasinya. Oleh karena itu, jumlah sampel yang akan menjadi responden pada penelitian ini adalah sebanyak 106 orang. Setelah dari pengumpulan data dari responden dan perusahaan terkumpul, maka langkah selanjutnya adalah menganalisis data dalam penelitian kuantitatif menggunakan statistik.

Menurut Sugiyono (2014) analisis deskriptif adalah mengalisis data dengan cara mendeskripsikan atau menggambarkan data yang telah terkumpul sebagaimana adanya tanpa bermaksud membuat kesimpulan yang berlaku untuk umum atau generalisasi. Tahap selanjutnya adalah melakukan pengelompokan data berdasarkan variabel dan jenis responden, lalu membuat tabel data berdasarkan item dari seluruh responden, kemudian menyajikan data dari setiap variabel dan melakukan perhitungan dari permasalahan. Penelitian ini menggunakan analisis jalur (path analysis) dengan menggunakan software SPSS24. Ghozali (2013) mengemukakan bahwa analisis jalur adalah penggunaan regresi untuk menaksir hubungan kausalitas antar variabel (model 
kausal) yang telah ditetapkan sebelumnya berdasarkan teori. Analisis jalur dikenal sebagai perluasan dari analisis linear berganda. Analisis jalur digunakan dalam menentukan pola hubungan antara tiga atau lebih variabel dan tidak dapat digunakan untuk mengkonfirmasi atau menolak hipotesis.

Langkah selanjutnya yaitu menghitung koefisien jalur menurut Sarwono (2011).

$$
\text { Pyxi }=\frac{\text { CRyxi }}{\text { CRyy }}
$$

Keterangan:

Pyxi $=$ Koefisien jalur dan dari variabel Xi terhadap variabel $\mathrm{Y}$

CRyxi $=$ Unsur atau elemen pada baris ke $\mathrm{Y}$ dan kolom ke Xi dari matriks invers

Cryy $=$ Unsur atau elemen pada baris Y dan kolom Y dari matriks invers

\section{Pengaruh Langsung dan Tidak Langsung}

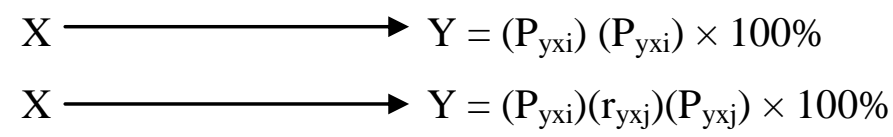

Untuk menguji seberapa besar inovasi, tanggung jawab, orientasi pada hasil, pengetahuan, proses pembelajaran dan motivasi pada budaya kerja yaitu menggunakan teknik korelasi ganda. Korelasi ganda (multiple correlate) adalah suatu nilai yang menunjukkan kuatnya pengaruh atau hubungan dua variabel atau lebih secara bersamasama dengan variabel lain (Riduwan, 2012). Korelasi ganda dapat dihitung dengan rumus sebagai berikut:

$$
R \times 1 \times 2 \times 3 \times 4=\sqrt{\frac{r_{y x_{1}}^{2}+r_{y x_{2}}^{2}+r_{y x}^{2}+r_{y x 4}^{2}-2 r_{y x_{1}} r_{y x_{2}} \quad x_{x 3}{ }_{y x 4} r_{x_{1} x_{2} \times 3 x 4}}{1-r_{x_{1} x_{2} \times 3 x_{4}}^{2}}}
$$

Keterangan:

$\mathrm{R}_{\mathrm{Y}} \mathrm{x} 1 \mathrm{x} 2 \mathrm{x} 3 \mathrm{x} 4=$ Korelasi antara variabel XI, X2, X3, X4 secara bersama-sama dengan variabel Y

ryXI $=$ Korelasi product moment antara XI dengan $\mathrm{Y}$

ryX2 $=$ Korelasi product moment antara X2 dengan $\mathrm{Y}$

ryX3 $=$ Korelasi product moment antara X3 dengan $\mathrm{Y}$

ryX4 = Korelasi product moment antara X4 dengan $\mathrm{Y}$

$\mathrm{rx} 1 \times 2 \times 3 \times 4=$ Korelasi product moment antara XI, X2, X3, X4 
Kemudian untuk mengetahui kontribusi pengaruh variabel $\mathrm{X}_{1}, \mathrm{X}_{2}, \mathrm{X}_{3}, \mathrm{X}_{4}, \mathrm{X}_{5}, \mathrm{X}_{6}$ terhadap Y yaitu dengan menggunakan rumus koefisien determinasi menurut Sugiyono (2012) sebagai berikut:

$$
\mathrm{Kd}=\mathbf{r}^{2} \times 100 \%
$$

Keterangan:

$$
\begin{array}{ll}
\mathrm{Kd} & =\text { Koefisien determinasi } \\
\mathrm{r} & =\text { Koefisien korelasi }
\end{array}
$$

Berikut ini merupakan kriteria untuk koefisien determinasi: 1) jika "kd" mendekati 0, maka pengaruh variabel X terhadap variabel Y lemah; 2) jika "kd" mendekati 1, maka pengaruh variabel $\mathrm{X}$ terhadap variabel $\mathrm{Y}$ kuat; 3) koefisiensi determinasi untuk melihat beberapa presentase (\%) variabel X1, X2, X3, X4, X5 dan X6 mempengaruhi variabel $\mathrm{Y}$.

Untuk memprediksi seberapa jauh perubahan nilai variabel dependen bila nilai variabel independen dirubah-rubah yaitu dengan menggunakan analisis regresi linier berganda. Sugiyono (2014) menyatakan bahwa analisis regresi ganda digunakan oleh peneliti untuk meramalkan bagaimana keadaan (naik turunnya) variabel dependen, bila dua variabel independen sebagai faktor prediktor dimanipulasi (dinaikturunkan nilainya). Analisis dapat dilakukan dengan rumus sebagai berikut:

$$
Y^{*}=\mathbf{a}+\mathbf{b}_{1} \mathbf{X}_{1}+\mathbf{b}_{2} \mathbf{X}_{2}+\mathbf{b}_{3} \mathbf{X}_{3}+\mathbf{b}_{4} \mathbf{X}_{4}+\mathbf{b}_{5} \mathbf{X}_{5}+\mathbf{b}_{6} \mathbf{X}_{6}
$$

Keterangan:

$\mathrm{Y}=$ Subjek dalam dependent variable yang diprediksikan

$\mathrm{X}=$ Independent variable

$\mathrm{a}=$ Harga Y ketika X = 0 (harga konstan)

$\mathrm{b}=$ Angka atau koefisien regresi yang menunjukan angka peningkatan ataupun penurunan dependent variable yang disebabkan pada perubahan independent variable.

Analisis regresi sederhana didasarkan pada hubungan fungional ataupun kausal satu variable independen dengan satu variabel dependen Menurut Sugiyono (2014) bahwa persamaan umum regresi linier sederhana adalah sebagai berikut:

$$
\mathbf{Y}^{\prime}=\mathbf{a}+\mathbf{b X}
$$


Keterangan:

$\mathrm{Y}^{\prime}=$ Subjek dalam variabel dependen yang diprediksikan

$\mathrm{a}=$ Harga $\mathrm{Y}^{\prime}$ bila $\mathrm{X}=0$ (harga konstan)

$\mathrm{b}=$ Angka arah atau koefisien regresi, yang menunujukan arah pengingkatan ataupun penurunan variabel dependen yang didasarkan pada variabel independen, bila $b$ (+) maka naik, dan bila (-) maka akan terjadi penurunan.

$\mathrm{X}=$ Subyek pada variabel independen yang mempunyai nilai tertentu

Menurut Ridwan (2012) untuk menguji signifikasi pengaruh variabel X terhadap Y digunakan rumus uji F sebagai berikut:

$$
\frac{R^{2}}{\frac{K}{\frac{\left(1-R^{2}\right)}{n-k-1}}}
$$

Keterangan:

$\mathrm{R}=$ Nilai koefisien korelasi ganda

$\mathrm{k}=$ Jumlah variabel bebas (independen)

$\mathrm{n} \quad=$ Jumlah sampel

R2 = Koefisien korelasi ganda yang telah ditentukan

$\mathrm{F} \quad$ = Fhitung yang selanjutnya akan dibandingkan dengan Ftabel

Uji hipotesis korelasi ganda langsung dikonsultasikan dengan harga $F_{\text {tabel }}$ dengan didasarkan pada $\mathrm{dk}$ pembilang $=\mathrm{k}$ dan $\mathrm{dk}$ penyebut $=(\mathrm{n}-\mathrm{k}-1)$ dan taraf kesalahan yang ditetapkan adalah $5 \%(0.05)$.

Uji t digunakan untuk mengetahui apakah secara parsial variabel bebas berpengaruh secara signifikan atau tidak terhadap variabel terikat (Riduwan, 2012). Jika $t_{\text {hitung }} \geq t_{\text {tabel }}$ dan sig $\leq \mathrm{a}$ maka H1 diterima dan H0 ditolak dan jika $t_{\text {hitung }} \leq t_{\text {tabel }}$ dan sig $\leq$ a maka $\mathrm{H} 1$ ditolak dan $\mathrm{H} 0$ diterima. 


\section{HASIL PENELITIAN}

\section{Analisis Jalur}

Tabel 1.

Hasil Koefisien Korelasi

\begin{tabular}{|c|c|c|c|c|c|c|c|c|}
\hline \multicolumn{9}{|c|}{ Correlations } \\
\hline & & $\mathrm{X} 1$ & $\mathrm{X} 2$ & X3 & $\mathrm{X} 4$ & $\mathrm{X} 5$ & X6 & $\mathrm{Y}$ \\
\hline \multirow[t]{3}{*}{$\mathrm{X} 1$} & Pearson Correlation & 1 & $.639^{* * *}$ & $.400^{* *}$ & $.267^{* *}$ & $.388^{* * *}$ & $.367^{* *}$ & $.334^{* *}$ \\
\hline & Sig. (2-tailed) & & .000 & .000 & .006 & .000 & .000 & .000 \\
\hline & $N$ & 106 & 106 & 106 & 106 & 106 & 106 & 106 \\
\hline \multirow[t]{3}{*}{$\mathrm{X} 2$} & Pearson Correlation & $.639^{* * *}$ & 1 & $.483^{* * *}$ & $.293^{* *}$ & $.415^{* * *}$ & $.442^{* * *}$ & $.312^{* * *}$ \\
\hline & Sig. (2-tailed) & .000 & & .000 & .002 & .000 & .000 & .001 \\
\hline & $N$ & 106 & 106 & 106 & 106 & 106 & 106 & 106 \\
\hline \multirow[t]{3}{*}{$\mathrm{X} 3$} & Pearson Correlation & $.400^{* * *}$ & $.483^{* * *}$ & 1 & $.527^{* * 3}$ & $.520^{* * *}$ & $.362^{* *}$ & $.276^{* *}$ \\
\hline & Sig. (2-tailed) & .000 & .000 & & .000 & .000 & .000 & .004 \\
\hline & $N$ & 106 & 106 & 106 & 106 & 106 & 106 & 106 \\
\hline \multirow[t]{3}{*}{$\mathrm{X} 4$} & Pearson Correlation & $.267^{* *}$ & $.293^{* * *}$ & $.527^{* *}$ & 1 & $.398^{* *}$ & $.522^{* *}$ & $.258^{* *}$ \\
\hline & Sig. (2-tailed) & .006 & .002 & .000 & & .000 & .000 & .008 \\
\hline & $N$ & 106 & 106 & 106 & 106 & 106 & 106 & 106 \\
\hline \multirow[t]{3}{*}{$\mathrm{X} 5$} & Pearson Correlation & $.388^{* *}$ & $.415^{* * *}$ & $.520^{* * *}$ & $.398^{* * *}$ & 1 & $.455^{* * *}$ & $.355^{* *}$ \\
\hline & Sig. (2-tailed) & .000 & .000 & .000 & .000 & & .000 & .000 \\
\hline & $N$ & 106 & 106 & 106 & 106 & 106 & 106 & 106 \\
\hline \multirow[t]{3}{*}{ X6 } & Pearson Correlation & $.367^{\text {** }}$ & $.442^{* * *}$ & $.362^{* * *}$ & $.522^{* * *}$ & $.455^{* *}$ & 1 & $.261^{* * *}$ \\
\hline & Sig. (2-tailed) & .000 & .000 & .000 & .000 & .000 & & .007 \\
\hline & $N$ & 106 & 106 & 106 & 106 & 106 & 106 & 106 \\
\hline \multirow[t]{3}{*}{$\mathrm{Y}$} & Pearson Correlation & $.334^{* * *}$ & $.312^{* * *}$ & $.276^{* * *}$ & $.258^{* * *}$ & $.355^{* *}$ & $.261^{* * 4}$ & 1 \\
\hline & Sig. (2-tailed) & .000 & .001 & .004 & .008 & .000 & .007 & \\
\hline & $N$ & 106 & 106 & 106 & 106 & 106 & 106 & 106 \\
\hline
\end{tabular}

(Sumber: Olah Data Peneliti, 2019)

Berdasarkan tabel 1, hasil perhitungan korelasi antar subvariabel menunjukkan bahwa hubungan nilai korelasi atara lain berada pada tingkatan hubungan cukup kuat dan rendah, dikarenakan interval koefisien berkisar antara 0,20 hingga 0,599.

Tabel 2.

Hasil Koefisien Jalur

\begin{tabular}{|c|c|c|c|c|c|c|}
\hline \multicolumn{7}{|c|}{ Coefficients $^{a}$} \\
\hline & \multirow[t]{2}{*}{ Model } & \multicolumn{2}{|c|}{$\begin{array}{c}\text { Unstandardized } \\
\text { Coefficients }\end{array}$} & \multirow{2}{*}{$\begin{array}{c}\begin{array}{c}\text { Standardized } \\
\text { Coefficients }\end{array} \\
\text { Beta } \\
\end{array}$} & \multirow[t]{2}{*}{$\mathbf{t}$} & \multirow[t]{2}{*}{ Sig. } \\
\hline & & B & Std. Error & & & \\
\hline \multirow[t]{7}{*}{1} & (Constant) & 5003.424 & 2184.773 & & 2.290 & .024 \\
\hline & Inovasi & .229 & .163 & .169 & 1.404 & .164 \\
\hline & Tanggung Jawab & .097 & .158 & .079 & .616 & .539 \\
\hline & Orientasi pada Hasil & .009 & .207 & .005 & .044 & .965 \\
\hline & Pengetahuan & .218 & .271 & .095 & .805 & .423 \\
\hline & Proses Pembelajaran & .451 & .249 & .207 & 1.809 & .073 \\
\hline & Motivasi & .019 & .120 & .018 & .156 & .876 \\
\hline
\end{tabular}

(Sumber: Olah Data Peneliti, 2019) 
Berdasarkan tabel 2, dapat diketahui bahwa koefisien dimensi inovasi pada budaya kerja sebesar 0,169 $\left(\mathrm{Pyx}_{1}\right)$, koefisien tanggung jawab pada budaya kerja sebesar 0,079 $\left(\mathrm{Pyx}_{2}\right)$, koefisien orientasi pada hasil pada budaya kerja sebesar 0,05 $\left(\mathrm{Pyx}_{3}\right)$, koefisisen pengetahuan pada budaya kerja sebesar 0,095 $\left(\mathrm{Pyx}_{4}\right)$, koefisien proses pembelajaran pada budaya kerja sebesar 0,207 $\left(\mathrm{Pyx}_{5}\right)$, dan koefisien motivasi pada budaya kerja sebesar 0,018 $\left(\mathrm{Pyx}_{6}\right)$. Hasil perhitungan di atas dilihat pada titik tabel beta.

\section{Pengaruh Langsung}

Hasil dari pengaruh langsung dapat diketahui dengan perhitungan berikut ini:

Pengaruh Langsung Inovasi (X1) pada Budaya Kerja Karyawan (Y)

$$
\begin{aligned}
& \left(\mathrm{Pyx}_{1}\right)\left(\mathrm{Pyx}_{1}\right) \times 100 \% \\
= & (0,169)(0,169) \times 100 \% \\
= & 2,85 \%
\end{aligned}
$$

\section{Pengaruh Langsung Tanggung Jawab (X2) pada Budaya Kerja Karyawan (Y)}

$$
\begin{aligned}
& \left(\mathrm{Pyx}_{2}\right)\left(\mathrm{Pyx}_{2}\right) \times 100 \% \\
= & (0,079)(0,079) \times 100 \% \\
= & 0,06 \%
\end{aligned}
$$

\section{Pengaruh Langsung Orientasi pada Hasil (X3) pada Budaya Kerja Karyawan (Y)}

$$
\begin{aligned}
& \left(\mathrm{Pyx}_{3}\right)\left(\mathrm{Pyx}_{3}\right) \times 100 \% \\
= & (0,005)(0,005) \times 100 \% \\
= & 2,5 \%
\end{aligned}
$$

\section{Pengaruh Langsung Pengetahuan (X4) pada Budaya Kerja Karyawan (Y)}

$$
\begin{aligned}
& \left(\mathrm{Pyx}_{4}\right)\left(\mathrm{Pyx}_{4}\right) \times 100 \% \\
= & (0,095)(0,095) \times 100 \% \\
= & 0,90 \%
\end{aligned}
$$


Pengaruh Langsung Proses Pembelajaran (X5) pada Budaya Kerja Karyawan (Y)

$$
\begin{aligned}
& \left(\mathrm{Pyx}_{5}\right)\left(\mathrm{Pyx}_{5}\right) \times 100 \% \\
= & (0,207)(0,207) \times 100 \% \\
= & 4,28 \%
\end{aligned}
$$

\section{Pengaruh Langsung Motivasi (X6) pada Budaya Kerja Karyawan (Y)}

$$
\begin{aligned}
& \left(\mathrm{Pyx}_{6}\right)\left(\mathrm{Pyx}_{6}\right) \times 100 \% \\
= & (0,018)(0,018) \times 100 \% \\
= & 0,03 \%
\end{aligned}
$$

Berdasarkan perhitungan di atas, total pengaruh langsung keenam variabel independen terhadap variabel dependen adalah sebesar 10,62\%.

\section{Pengaruh Tidak Langsung}

Total pengaruh antara variabel $\mathrm{X}$ dan variabel $\mathrm{Y}$ adalah $18,35 \%$. Hal ini dapat dilihat dari penjelasan perhitungan di bawah ini:

\section{Pengaruh Inovasi (X1) pada Budaya Kerja Karyawan (Y)}

$$
\begin{aligned}
& =(2,8 \%)+(0,9 \%)+(0,5 \%)+(0,04 \%)+(1,4 \%)+(0,2 \%) \\
& =5,6 \%
\end{aligned}
$$

Pengaruh Tanggung Jawab (X2) pada Budaya Kerja Karyawan (Y)

$$
\begin{aligned}
& =(0,6 \%)+(0,8 \%)+(0,2 \%)+(0,2 \%)+(0,6 \%)+(0,06 \%) \\
& =2,46 \%
\end{aligned}
$$

\section{Pengaruh Orientasi pada Hasil (X3) pada Budaya Kerja Karyawan (Y)}

$$
\begin{aligned}
& =(0,25, \%)+(0,38 \%)+(0,019 \%)+(0,025 \%)+(0,053 \%)+(0,032 \%) \\
& =0,13 \%
\end{aligned}
$$

\section{Pengaruh Pengetahuan (X4) pada Budaya Kerja Karyawan (Y)}

$$
\begin{aligned}
& =(0,9 \%)+(0,4 \%)+(0,22 \%)+(0,025 \%)+(0,7 \%)+(0,089 \%) \\
& =2,4 \%
\end{aligned}
$$




\section{Pengaruh Proses Pembelajaran (X5) pada Budaya Kerja Karyawan (Y)}

$$
\begin{aligned}
& =(4,2 \%)+(1,3 \%)+(0,6 \%)+(0,025 \%)+(0,7 \%)+(0,08 \%) \\
& =7,3 \%
\end{aligned}
$$

\section{Pengaruh Motivasi (X5) pada Budaya Kerja Karyawan (Y)}

$$
\begin{aligned}
& =(0,03 \%)+(0,16 \%)+(0,06 \%)+(0,03 \%)+(0,08 \%)+(0,1 \%) \\
& =0,46 \%
\end{aligned}
$$

\begin{tabular}{|c|c|c|c|c|}
\hline \multicolumn{5}{|c|}{ Model Summary } \\
\hline Model & $\mathbf{R}$ & R Square & Adjusted R Square & Std. Error of the Estimate \\
\hline 1 & $.431^{\mathrm{a}}$ & .185 & .136 & 2989.050 \\
\hline \multicolumn{5}{|c|}{$\begin{array}{c}\text { a. Predictors: (Constant), Motivasi, Orientasi pada Hasil, Inovasi, Proses Pembelajaran, Pengetahuan, } \\
\text { Tanggung Jawab }\end{array}$} \\
\hline
\end{tabular}

\section{Koefisien Korelasi Ganda}

\section{Tabel 3.}

Koefisien Korelasi Antara $X_{1}, X_{2}, X_{3}, X_{4}, X_{5}, X_{6}$ pada $Y$

\section{Koefisien Determinasi}

Berdasarkan hasil analisis, diketahui bahwa: $\mathrm{r}=0,431$, sehingga dapat diperoleh perhitungan sebagai berikut:

$$
\begin{aligned}
\mathrm{Kd} & =0,431^{2} \times 100 \% \\
& =0,185 \times 100 \% \\
& =18,5 \%
\end{aligned}
$$

Selanjutnya perhitungan pengaruh dari variabel lain, maka diperoleh hasil sebagai berikut:

Diketahui: $\mathrm{r}^{2}=0,185$

$$
\begin{aligned}
& \mathrm{Py}^{\varepsilon}=(1-0,185) \times 100 \% \\
& \mathrm{Py}^{\varepsilon}=0,815 \text { atau } 81,5 \%
\end{aligned}
$$

Berdasarkan perhitungan diatas dapat disimpulkan bahwa pengaruh inovasi, tanggung jawab, orientasi pada hasil, pengetahuan, proses pembelajaran dan motivasi pada budaya kerja adalah 0,185 atau $18,5 \%$ dan sisanya dipengaruhi oleh variabel lain yang tidak diteliti yaitu sebesar 0,815 atau $81,5 \%$. 


\section{Analisis Regresi Linear Berganda}

Tabel 4.

Perhitungan Regresi Linear Berganda

\begin{tabular}{|c|c|c|c|c|c|c|}
\hline \multicolumn{7}{|c|}{ Coefficients $^{a}$} \\
\hline & \multirow[t]{2}{*}{ Model } & \multicolumn{2}{|c|}{$\begin{array}{c}\text { Unstandardized } \\
\text { Coefficients }\end{array}$} & \multirow{2}{*}{$\begin{array}{c}\begin{array}{c}\text { Standardized } \\
\text { Coefficients }\end{array} \\
\text { Beta }\end{array}$} & \multirow[t]{2}{*}{$\mathbf{t}$} & \multirow[t]{2}{*}{ Sig. } \\
\hline & & B & Std. Error & & & \\
\hline \multirow[t]{7}{*}{1} & (Constant) & 5003.424 & 2184.773 & & 2.290 & .024 \\
\hline & Inovasi & .229 & .163 & .169 & 1.404 & .164 \\
\hline & Tanggung Jawab & .097 & .158 & .079 & .616 & .539 \\
\hline & Orientasi pada Hasil & .009 & .207 & .005 & .044 & .965 \\
\hline & Pengetahuan & .218 & .271 & .095 & .805 & .423 \\
\hline & Proses Pembelajaran & .451 & .249 & .207 & 1.809 & .073 \\
\hline & Motivasi & .019 & .120 & .018 & .156 & .876 \\
\hline
\end{tabular}

(Sumber: Olah Data Peneliti, 2019)

Berdasarkan hasil diatas, maka dapat diperoleh persamaan sebagai berikut:

$$
\widehat{Y}=5003,424+0,229 X_{1}+0,097 X_{2}+0,009 X_{3}+0,218 X_{4}+0,451 X_{5}+0,019 X_{6}
$$

Data tabel 4 juga menunjukkan bahwa terdapat pengaruh postif antara $X_{1}, X_{2}$, $\mathrm{X}_{3}, \mathrm{X}_{4}, \mathrm{X}_{5}, \mathrm{X}_{6}$, maka budaya kerja karyawan akan terus meningkat apabila inovasi, tanggung jawab, orientasi pada hasil, pengetahuan, proses pembelajaran dan motivasi ditingkatkan.

\section{Anaisis Regresi Linear Sederhana}

\section{Hasil Perhitungan Regresi Linear Sederhana Inovasi (X1)}

Tabel 5.

Hasil Perhitungan Regresi Linier Sederhana Inovasi

\begin{tabular}{|c|c|c|c|c|c|c|}
\hline \multicolumn{7}{|c|}{ Coefficients $^{a}$} \\
\hline \multirow{2}{*}{\multicolumn{2}{|c|}{ Model }} & \multicolumn{2}{|c|}{ Unstandardized Coefficients } & \multirow{2}{*}{$\begin{array}{c}\text { Standardized Coefficients } \\
\text { Beta }\end{array}$} & \multirow{2}{*}{$\mathbf{t}$} & \multirow{2}{*}{ Sig. } \\
\hline & & B & Std. Error & & & \\
\hline \multirow{2}{*}{1} & (Constant) & 8304.085 & 1761.298 & & 4.715 & .000 \\
\hline & INOVASI & .454 & .125 & .334 & 3.617 & .000 \\
\hline
\end{tabular}

Berdasarkan tabel 5, diketahui bahwa terdapat pengaruh positif antara inovasi (variabel X1) pada budaya kerja karyawan (variabel Y). Oleh karena itu, budaya kerja dapat meningkat jika inovasi (X1) ditingkatkan. 


\section{Hasil Perhitungan Regresi Linear Sederhana Tanggung Jawab (X2)}

Tabel 6.

Hasil Perhitungan Regresi Linier Sederhana Tanggung Jawab

\begin{tabular}{|c|c|c|c|c|c|c|}
\hline \multicolumn{7}{|c|}{ Coefficients $^{a}$} \\
\hline & \multirow{2}{*}{ Model } & \multicolumn{2}{|c|}{ Unstandardized Coefficients } & \multirow{2}{*}{$\frac{\text { Standardized Coefficients }}{\text { Beta }}$} & \multirow{2}{*}{$\mathbf{t}$} & \multirow{2}{*}{ Sig. } \\
\hline & & B & Std. Error & & & \\
\hline \multirow[t]{2}{*}{1} & $($ Constant $)$ & 9188.723 & 1640.392 & & 5.602 & .000 \\
\hline & Tanggung Jawab & .383 & .114 & .312 & 3.345 & .001 \\
\hline & dent Variable: $\mathrm{Bu}$ & ya Kerja & & & & \\
\hline
\end{tabular}

Berdasarkan dari hasil tabel 6, diketahui terdapat pengaruh positif antara tanggung jawab (variabel X2) pada budaya kerja karyawan (variabel Y). Oleh karena itu, budaya kerja akan meningkat jika tanggung jawab (X2) ditingkatkan.

\section{Hasil Perhitungan Regresi Linear Sederhana Orientas pada Hasil (X3)}

Tabel 7.

Hasil Perhitungan Regresi Linier Sederhana Orientasi pada Hasil

\begin{tabular}{|c|c|c|c|c|c|c|}
\hline \multicolumn{7}{|c|}{ Coefficients $^{a}$} \\
\hline & \multirow{2}{*}{ Model } & \multicolumn{2}{|c|}{ Unstandardized Coefficients } & \multirow{2}{*}{$\frac{\text { Standardized Coefficients }}{\text { Beta }}$} & \multirow{2}{*}{$\mathbf{t}$} & \multirow{2}{*}{ Sig. } \\
\hline & & B & Std. Error & & & \\
\hline \multirow[t]{2}{*}{1} & $($ Constant $)$ & 9852.902 & 1645.448 & & 5.988 & .000 \\
\hline & Orientasi pada Hasil & .463 & .158 & .276 & 2.925 & .004 \\
\hline
\end{tabular}

a. Dependent Variable: Budaya Kerja

(Sumber: Olah Data Peneliti, 2019)

Berdasarkan tabel 7, diketahui bahwa terdapat pengaruh positif antara orientasi pada hasil (variabel X3) pada budaya kerja karyawan (variabel Y). Penerapan Budaya kerja akan meningkat, jika orientasi pada hasil (X3) ditingkatkan.

\section{Hasil Perhitungan Regresi Linear Sederhana Pengetahuan (X4)}

Tabel 8.

Hasil Perhitungan Regresi Linier Sederhana Pengetahuan

\begin{tabular}{|c|c|c|c|c|c|c|}
\hline \multicolumn{7}{|c|}{ Coefficients $^{a}$} \\
\hline & \multirow{2}{*}{ Model } & \multicolumn{2}{|c|}{ Unstandardized Coefficients } & \multirow{2}{*}{$\begin{array}{c}\text { Standardized Coefficients } \\
\text { Beta }\end{array}$} & \multirow{2}{*}{$\mathbf{t}$} & \multirow{2}{*}{ Sig. } \\
\hline & & B & Std. Error & & & \\
\hline \multirow[t]{2}{*}{1} & (Constant) & 10811.429 & 1416.693 & & 7.631 & .000 \\
\hline & Pengetahuan & .591 & .217 & .258 & 2.726 & .008 \\
\hline
\end{tabular}

a. Dependent Variable: Budaya Kerja

(Sumber: Olah Data Peneliti, 2019) 
Berdasarkan hasil analisis pada tabel 8, diketahui bahwa terdapat pengaruh positif antara pengetahuan (variabel X4) pada budaya kerja karyawan (variabel Y). Oleh karena itu, budaya kerja akan meningkat jika pengetahuan (X4) ditingkatkan.

\section{Hasil Perhitungan Regresi Linear Sederhana Proses Pembelajaran (X5)}

\section{Tabel 9.}

Hasil Perhitungan Regresi Linier Sederhana Proses Pembelajaran

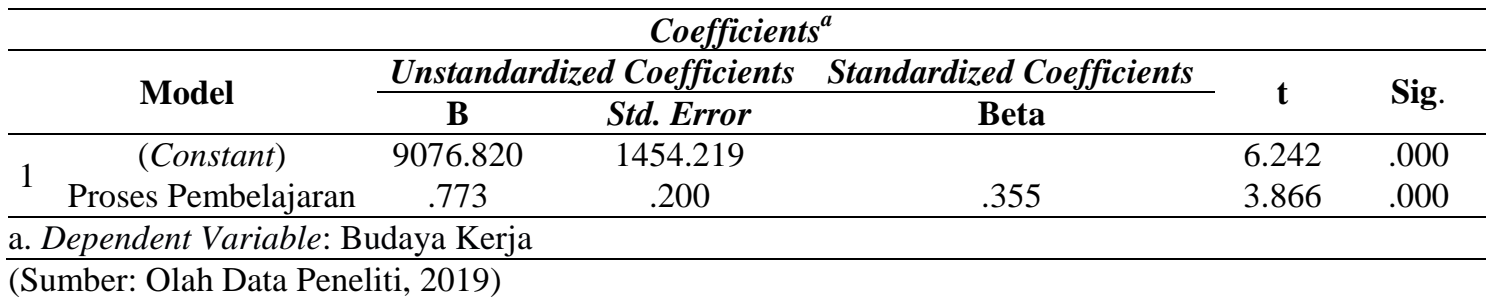

Berdasarkan tabel 9, hasil menunjukkan bahwa terdapat pengaruh positif antara proses pembelajaran (variabel X5) pada budaya kerja karyawan (variabel Y). Dengan begitu, budaya kerja akan meningkat jika proses pembelajaran (X5) ditingkatkan.

\section{Hasil Perhitungan Regresi Linear Sederhana Motivasi (X6)}

Tabel 10.

Hasil Perhitungan Regresi Linier Sederhana Motivasi

\begin{tabular}{|c|c|c|c|c|c|c|}
\hline \multicolumn{7}{|c|}{ Coefficients $^{a}$} \\
\hline & \multirow{2}{*}{ Model } & \multicolumn{2}{|c|}{ Unstandardized Coefficients } & \multirow{2}{*}{$\frac{\text { Standardized Coefficients }}{\text { Beta }}$} & \multirow{2}{*}{$\mathbf{t}$} & \multirow{2}{*}{ Sig. } \\
\hline & & B & Std. Error & & & \\
\hline \multirow{2}{*}{1} & $($ Constant $)$ & 9823.690 & 1750.757 & & 5.611 & .000 \\
\hline & Motivasi & .268 & .097 & .261 & 2.761 & .007 \\
\hline
\end{tabular}

(Sumber: Olah Data Peneliti, 2019)

Berdasarkan tabel 10, data menunjukkan bahwa terdapat pengaruh positif antara motivasi (variabel X6) pada budaya kerja karyawan (variabel Y). Hal ini bermakna bahwa budaya kerja akan meningkat, jika motivasi (X6) ditingkatkan. 


\section{Uji Simultan}

Tabel 11.

Perhitungan Uji F

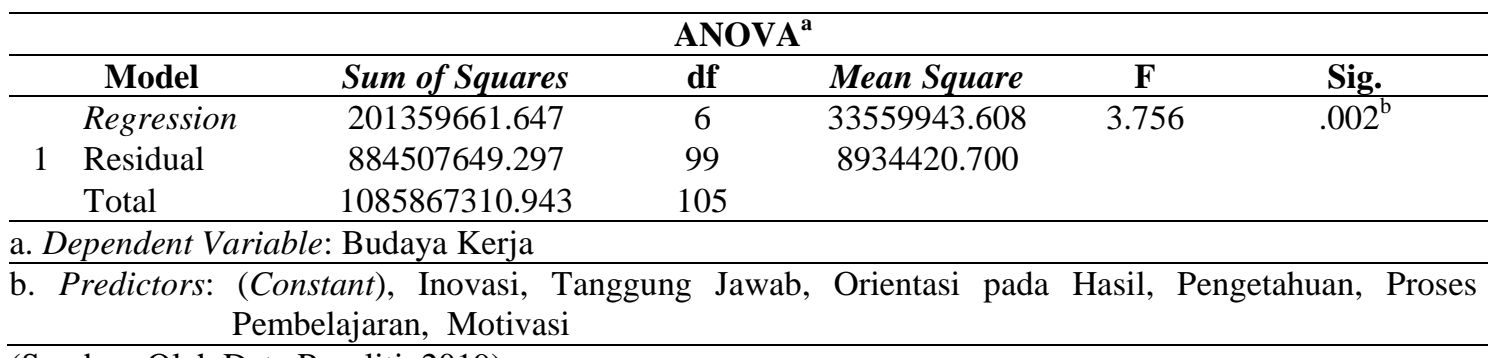

(Sumber: Olah Data Peneliti, 2019)

Berdasarkan perhitungan pada tabel 11, diperoleh hasil $F_{\text {hitung }}$ sebesar 3,756, sehingga dapat disimpulkan bahwa $F_{\text {hitung }}$ lebih besar dari $F_{\text {tabel, }}$ yakni 3,756 2,191. Selain $\mathrm{F}_{\text {hitung }}$ dari tabel juga dapat dilihat nilai regresi memiliki tingkat signifikasi 0.002, nilai ini lebih kecil dari 0.05 atau nilai $\operatorname{Sig} \leq$ a. Hal ini menunjukkan bahwa keenam variabel yaitu inovasi, tanggung jawab, orientasi pada hasil, pengetahuan, proses pembelajaran dan motivasi berpengaruh secara positif dan signifikan terhadap budaya kerja sebagai variabel terkaitnya.

\section{Uji Hipotesis Parsial (Uji t)}

Hasil analisis uji t menunjukkan bahwa pengaruh inovasi terhadap budaya kerja karyawan (dependent variable) adalah sebesar 3,617, maka dari dua variabel tersebut terdapat pengaruh yang signifikan. Adapun hasil analisis hubungan inovasi terhadap budaya kerja karyawan adalah sebesar 3,345, maka ini menunjukkan bahwa dua variabel tersebut memiliki pengaruh yang signifikan. Selanjutnya hubungan orientasi pada hasil terhadap budaya kerja karyawan adalah sebesar 2,925, maka kedua variabel tersebut juga memiliki pengaruh yang signifikan.

Hubungan pengetahuan terhadap budaya kerja karyawan adalah sebesar 2,726, maka ini bermakna bahwa terdapat pengaruh yang signifikan antara kedua variabel tersebut. Selanjutnya hubungan proses pembelajaran terhadap budaya kerja karyawan adalah sebesar 3,866. Hal ini menunjukkan bahwa kedua variabel tersebut memiliki pengaruh yang signifikan. Adapun hubungan motivasi terhadap budaya kerja karyawan adalah sebesar 2,761, artinya kedua variabel tersebut juga memiliki pengaruh yang signifikan. 


\section{PEMBAHASAN}

Budaya kerja pada suatu perusahaan atau organisasi mulai terbentuk sejak satuan kerja atau perusahaan tersebut berdiri. Pemebentukan budaya kerja dapat terjadi ketika perusahaan menghadapi suatu permasalahan yang berkenaan dengan keberlangsungan perusahaan yang terkait dengan perubahan-perubahan eksternal maupun internal. Budaya kerja terdiri dari dua indikator yang bersifat positif dan negatif. Budaya kerja yang positif dapat berupa perilaku ramah-tamah, gotong-royong, perilaku kerja keras dan optimis. Adapun budaya kerja yang negatif dapat berupa tidak disiplin, tidak jujur, tidak tegas dan tidak percaya diri (Safrizal et al., 2014).

Menurut Latif et al., (2016) budaya kerja pada umumnya merupakan pernyataan filosofis yang dapat diterapkan sebagai tuntutan yang mengikat para karyawan karena dapat diformulasikan secara formal dalam berbagai peraturan dan ketentuan. Sebagai salah satu acuan bagi ketentuan atau peraturan yang berlaku, maka para pemimpin dan pegawai secara tidak langsung akan terikat pada peraturan tersebut sehingga dapat membentuk sikap dan perilaku sesuai dengan visi dan misi serta strategi. Proses pembentukan tersebut pada akhirnya akan menghasilkan pemimpin dan karyawan profesional yang mempunyai integritas yang tinggi. Budaya kerja bertujuan untuk mengubah sikap dan juga perilaku karyawan atau sumber daya manusia (SDM) yang ada agar dapat meningkatkan produktifitas kerja untuk menghadapi berbagai tantangan di masa yang akan datang.

Hasil penelitian menunjukkan bahwa inovasi, tanggung jawab, orientasi pada hasil, pengetahuan, proses pembelajaran dan motivasi menunjukan adanya pengaruh yang positif dan signifikan terhadap budaya kerja karyawan. Hal ini sejalan dengan penelitian yang dilakukan oleh Apriyanti (2008) yang menyimpulkan bahwa terdapat enam faktor yang mempengaruhi budaya kerja, yakni: (1) inovasi; (2) tanggung jawab; (3) orientasi pada hasil; (4) pengetahuan; (5) sistem kerja; (6) motivasi.

Hasil penelitian ini juga menunjukkan bahwa dimensi sikap terhadap pekerjaan dan perilaku terhadap waktu bekerja hanya berpengaruh sebesar $18,5 \%$ pada budaya kerja, sedangkan sisanya sebesar $81,5 \%$ dipengaruhi oleh faktor lain yang tidak diteliti dalam penelitian ini. Londong (2011) menyebutkan ada delapan faktor yang memengaruhi budaya kerja karyawan, yaitu: (1) seleksi pekerja; (2) budaya organisasi; 
(3) budaya luar; (4) misi perusahaan; (5) proses pembelajaran; (6) keinginan untuk diakui; (7) keinginan untuk berprestasi; (8) keinginan untuk terpenuhinya rasa aman.

Budaya kerja merupakan sistem nilai, persepsi, perilaku dan keyakinan yang dianut oleh tiap individu karyawan dan kelompok karyawan tentang makna kerja dan refleksinya dalam kegiatan mencapai tujuan organsiasi dan individual (Londong, 2011). Sudut pandang yang negatif terhadap kerja dapat menghambat timbulnya budaya kerja pada pegawai. Menurut Darmawan (2013) terdapat beberapa faktor yang menghambat budaya kerja, yaitu: (1) prasangka buruk; (2) prinsip yang tidak sesuai; (3) pengalaman pahit; (4) prioritas yang rendah terhadap kerja; (5) sudut pandang yang negatif terhadap kerja; (6) pembanding; (7) literatur. Sinha et al. (2010), dalam penelitiannya juga mengemukakan bahwa budaya yang berbeda (different culture) antara organisasi dan pekerja merupakan suatu hambatan dalam budaya kerja.

\section{SIMPULAN}

Berdasarkan hasil penelitian dan pembahasan mengenai analisis faktor-faktor budaya kerja karyawa PD. RAM Armalia Sukabumi, maka dapat diambil kesimpulan sebagai berikut: 1) inovasi, tanggung jawab, orientasi pada hasil, pengetahuan, proses pembelajaran dan motivasi menunjukan adanya pengaruh yang positif dan signifikan terhadap budaya kerja karyawan; 2) dalam dimensi sikap terhadap pekerjaan dan perilaku terhadap waktu bekerja menunjukkan pengaruh sebesar $18,5 \%$ pada budaya kerja, sisanya sebesar $81,5 \%$ dipengaruhi oleh faktor lain; 3) total pengaruh langsung dan tidak langsung antara variabel inovasi (X1), tanggung jawab (X2), orientasi pada hasil (X3), pengetahuan (X4), proses pembelajaran (X5), motivasi (X6) pada budaya kerja (Y) masing-masing adalah 10,62\% dan 18,35\%.

\section{DAFTAR PUSTAKA}

Apriyanti, I. (2008). Work Culture Among Argo-Entrepreneurs. Tesis. Universitas Putra Malaysia

Arikunto, S. (2010). Prosedur Penelitian Suatu Pendekatan Praktik. Jakarta: Rineka Cipta

Bohlander, G., \& Snell, S. (2010). Principles of Human Resource, Management, 15th $E d$. South Western: Mason, $\mathrm{OH}$

Darmawan, D. (2013). Prinsip-Prinsip Perilaku Organisasi. Surabaya: PT. Temprina Media Grafika 
Gering, G., Supriyadi, S., \& Triguno, T. (2001). Budaya Kerja Organisasi Pemerintah. Jakarta: Gramedia Pustaka Utama

Ghozali, I. (2013). Aplikasi Analisis Multivariate dengan Program IBM SPSS 21 Update PLS Regresi. Semarang: Badan Penerbit Universitas Diponegoro

Hasibuan, M. S. P. (2011). Manajemen Sumber Daya Manusia. Jakarta: PT. Bumi Aksara

Latif, I. N., Sari, D. R., \& Jonathan, R. (2016). Pengaruh Budaya Kerja terhadap Kinerja Pegawai pada Badan Kesatuan Bangsa dan Politik Kabupaten Kutai Timur. Ekonomia, 5(1), 450-455

Londong, D. (2011). Budaya Kerja. http://deddylodong.blogspot.com/2011-kerja-html Mahanani, I. W., Lubis, N., \& Widiartanto, W. (2014). Pengaruh Budaya Kerja dan Kepuasan Kerja terhadap Kinerja Karyawan dengan Komitmen Karyawan Sebagai Variabel Antara (Studi Kasus pada Karyawan Bagian Produksi Cetak Surat Kabar PT. Masscom Graphy Semarang). Jurnal Ilmu Administrasi Bisnis, 3(4), 355-365

Mangkunegara, A. A. A. P. (2005). Manajemen Sumber daya Manusia Perusahaan. Bandung: PT. Remaja Rosdakarya

Nawawi, H. (2003). Manajemen Sumber Daya Manusia untuk Bisnis yang Kompetitif. Yogyakarta: Gajah Mada University Press

Ndraha, T. (2005). Teori Budaya Organisasi, Cetakan Pertama. Jakarta: PT. Rineka Cipta

Riduwan, R. (2012). Dasar-Dasar Statistika. Bandung: Alfabeta

Safrizal, S., Said, M., \& Syafruddin, C. (2014). Pengaruh Budaya Kerja, Kemampuan dan Komitmen Pegawai terhadap Kinerja Pegawai serta Dampaknya pada Kinerja Dinas Pertambangan dan Energi Aceh. Jurnal Manajemen, 3(2), 44-53

Sarwono, J. (2011). Mixed Method: Cara Menggabungan Riset Kuantitatif dan Riset Kualitatif Secara Benar. Jakarta: PT. Elex Media Komputindo

Schein, E. H. (2010). Organizational Culture and Leadership. San Francisco: Jossey Bass

Setiadi, M. E. (2013). Ilmu Sosial Budaya Dasar. Jakarta: Kencana

Sinha, S., Singh, A. K. R., \& Dutt, R. (2010). Impact of Work Culture on Motivation Level of Employees in Selected Public Sector Companies in India. Delhi Business Review, 11(1), 41-54

Sugiyono, S. (2014). Metode Penelitian Pendidikan Pendekatan Kuantitatif, Kualitatif dan $R \& D$. Bandung: Alfabeta 